\title{
Arte autônoma ou arte política?
}

Bruno Daniel Bianchi ${ }^{1}$

\section{Resumo:}

O presente artigo tem por objetivo compreender a discussão entre a alternativa entre uma arte autônoma e uma arte política/de tendência. A partir do referencial teórico do marxista húngaro György Lukács, o texto busca criticar o caráter enrijecido do debate devido à limitação da concepção de sujeito e sociedade inerente à ideologia burguesa, assim como sua tentativa de produzir uma filosofia da arte desvinculada das questões histórico-sociais de seu tempo.

Palavras-chave: partidarismo; arte de tendência; autonomia da arte.

\section{Autonomous art or political art?}

\begin{abstract}
:
This article aims to understand the discussion between an autonomous art and a tendency/political art. Based on the theoretical reference of the Hungarian Marxist Gyorgy Lukacs, the paper seeks to criticize the stiffened character of the debate due to the limitation of the conception of subject and society inherent in bourgeois ideology, as well as its attempt to produce a philosophy of art detached from the historical-social questions of its time.
\end{abstract}

Keywords: partisanship; tendency art; autonomy of art.

O debate entre a politização ou não da obra de arte, ainda que presente há pelo menos 150 anos, é bastante recente na história da arte. Ainda que a obra passe por um processo de autonomização, por exemplo, de instituições como a religião já no Renascimento, é apenas com o desenvolvimento de teorias estéticas como as obras de Kant e Schiller que se tem início uma discussão sobre uma arte livre ou pura (BÜRGER, 2017). Como consequência, abre-se também a discussão sobre a possibilidade (ou exigência, em alguns casos) da arte assumir abertamente uma função política. A questão da existência de uma "contaminação" da arte pela política ou da existência de uma arte pura, acima dos debates e lutas do cotidiano ainda é um tema recorrente quando tratamos da relação entre arte e sociedade.

\footnotetext{
${ }^{1}$ Especialista em Gestão Pública pela Universidade Estadual de Ponta Grossa. E-mail: brunodbianchi@gmail.com.
} 
Em primeiro lugar, esse debate sobre a politização ou não da arte se revela como uma discussão mais geral da relação entre forma e conteúdo, na qual, por um lado, a visão de uma "arte pura" (ou uma arte pela arte) seria uma exacerbação da forma em detrimento do conteúdo, ou seja, colocaria o conteúdo em segundo plano. Por outro lado, a "arte política" (ou arte de tendência) representaria uma inflação do conteúdo, da priorização dos temas e tópicos de conteúdo político, de agitação e propaganda, sobre os aspectos mais formais das obras.

Isto se dá pela interpretação não-dialética da relação entre forma e conteúdo, pela rígida e inflexível tentativa tanto de autores quanto de críticos de perceber aquilo que Hegel definiu de uma perspectiva idealista: “o conteúdo não é senão o mudar da forma em conteúdo, e a forma não é senão o mudar do conteúdo em forma" (HEGEL, 1995). Não é, contudo, do da alçada deste texto responder à relação entre forma e conteúdo, sendo aqui somente necessário apontar como essa priorização de um ou de outro leva, inevitavelmente, a erros e obstáculos teóricos e práticos.

Mais importante neste momento é ressaltar a polarização entre aqueles que acreditam na possibilidade de uma "arte pela arte", autônoma, ou como colocava Lukács (2010), a arte na torre de marfim, e aqueles que defendiam a tarefa da arte de tomar posição e intervir diretamente nas lutas sociais - uma arte dirigida por uma tendência política. Historicamente, não faltaram representantes destas duas perspectivas, inclusive dentro dos próprios movimentos socialistas, como o caso da União Soviética² .

Em aparência, este debate gera um impasse: deve a arte sujeitar-se a uma direção política (seja ela interna ou externa) ou o artista deve ser um sujeito desinteressado, distanciado das mazelas sociais de sua época?

Aqui, antes de tudo, devemos deixar claro o que significa a arte de tendência na sua origem. Sem a intenção de entrar de modo aprofundado no aspecto histórico da questão, o debate sobre a politização da arte já está presente na primeira metade do século XIX, tendo, inclusive, participação ativa do jovem Marx. Em uma época de forte mobilização política (nos anos anteriores às revoluções de 1848 que tomaram conta da Europa), entra em debate se o poeta deve tomar partido (a visão, por exemplo de Herwegh) ou se, como sugeriria Freiligrath, o poeta estaria em uma torre de observação mais

\footnotetext{
${ }^{2}$ Aqui, dois grupos são de relevância: o LEF, que defendia uma arte "operativa”, de intervenção direta sobre a realidade (através, por exemplo, do agitprop), que buscava unir atividade artística com a produção em geral, chegando ao ponto de anunciar "abaixo à arte! Viva a técnica!", ou seja, anulando a especificidade do reflexo artístico; e o Proletkult, que buscava principalmente produzir uma "cultura proletária", através, principalmente, de mudanças linguísticas e formais. Ambos os movimentos - utilitaristas em essência - foram influentes após a Revolução Russa, tendo seu fim decretado com a institucionalização do Realismo Socialista em 1934.Sobre os movimentos artísticos soviéticos, ver Napolitano (1997) e Frederico (2018).
} 
alta que as muralhas do partido3. O próprio termo "tendência" ganharia notoriedade por servir de título a um poema de Heinrich Heine.

O que significa o termo "tendência"? Como este surge no contexto prussiano do século XIX? De início, vale apontar que o termo "tendência" precede seu uso estético, como feito por Herwegh, Freiligrath, Heine e outros. Sua origem pode ser encontrada na crítica de Marx à censura prussiana. Aqui, Marx critica a evidente parcialidade do órgão censor do estado, que defende a publicação "livre" quando o estado concorda com a tendência do escritor, mas é "extremamente exigente quando a tendência do autor não é prescrita pela lei” (LIFSCHITZ, 1933, p. 63).

Portanto, a "tendência", inicialmente, revelava um teor de censura reacionária - teor que, ao ser transposto para o campo propriamente estético não é completamente apagado, embora não possua o caráter literal visto no caso do estado prussiano. Isto porque, como apontou Lukács, tendência é algo bastante relativo: "uma obra aparece como 'tendenciosa' quando possui uma base classista e é hostil à orientação dominante - em termos de classe; a própria 'tendência' não é realmente uma tendência, mas sim somente aquela do oponente" (LUKÁCS, 1971, p. 25). Em outras palavras: uma arte é "tendenciosa" se posiciona-se criticamente ao status quo, à ordem estabelecida, seja ela uma ordem estética ou sócio-política. Se antes a censura vinha na forma do estado e da lei, agora há uma censura da própria instituição arte que retira o status de obra de arte de forma arbitrária, seguindo um ideal de “arte pura”. Não é incomum o valor estético de uma obra entrar em questão quando há uma tendência política explícita na sua representação especialmente se é uma tendência que ataca de frente a ordem estabelecida.

Não é à toa que, justamente devido a esse posicionamento reacionário - ainda hoje presente, inclusive entre autores "progressistas" - houve uma certa defesa da "tendência" da produção artística. Contrário à visão ideal da arte como "ausência de tendência", defendeu-se uma arte politizada, engajada, inclusive tendenciosa, sem perceber que, ao aceitar participar desse jogo de palavras do idealismo burguês, não se fez nada além que aceitar a derrota. Pois para existir um ramo da arte que seja "tendenciosa", que possua "tendência", assume-se a priori a existência de uma "arte pura", isenta e apartidária.

Antes, portanto, de cair na armadilha burguesa da "arte pura", precisamos compreender melhor o conceito de autonomia da obra de arte que subjaz o ideal de arte pura ou arte livre. Para entendermos o conceito, é preciso em primeiro lugar compreendê-lo como produto de um desenvolvimento histórico-social, e não como um aspecto inerente da atividade em si.

\footnotetext{
3 Para saber mais sobre o debate entre Herwegh e Freiligrath, ver o texto Tendência ou partidariedade? (1932), de Lukács, ou a obra A filosofia da arte de Karl Marx, de M. Lifschitz.
} 
A relação da autonomia da arte historicamente é tanto um tema da estética propriamente dita quanto da história da arte. Nesta, podemos destacar o papel sempre presente da determinação social da produção artística, determinação não no sentido do materialismo vulgar, de uma instância superior (a sociedade), que determinaria uma instância inferior (a atividade do sujeito). Neste sentido, podemos exemplificar o papel da pólis na atividade artística da Grécia Antiga, ou o papel a que ocupou a Igreja durante a Idade Média, ou a participação dos mecenas durante o período do Renascimento sendo que nestes últimos dois exemplos, é óbvio o caráter de "encomenda" da arte.

Ora, no presente, a ideia de uma arte "encomendada" certamente atribuiria a si olhares de escárnio, visto que a arte seria imposta de fora, por uma força alheia à própria subjetividade do artista. Entretanto, dificilmente alguém questionará o valor estético da Pietà de Michelangelo ou $A$ ronda noturna de Rembrandt, por exemplo, por sua característica de encomenda.

É, portanto, apenas com a consolidação da sociedade capitalista e da ordem burguesa no século XIX que se institui o ideal de uma arte autônoma, livre das amarras dos curadores e dos órgãos institucionais como a Igreja e o estado. Entretanto, isso não significa uma liberdade total das determinações sociais, mas apenas que os elementos constituintes dessa determinação social são radicalmente alterados com a consolidação da sociedade capitalista. É esta complexidade do local que a produção artística ocupa dentro da produção em geral que permite a Bürger definir a autonomia da arte como uma "categoria da sociedade burguesa, que, a um só tempo, torna reconhecível e dissimula um desenvolvimento histórico real” (2017, p. 87).

$\mathrm{O}$ autor segue avaliando a relação entre o surgimento da autonomia da arte e seu desligamento da práxis vital, de sua vinculação imediata ao sagrado. É de importância fundamental a consideração de Bürger de que, para atingir o seu novo status na sociedade capitalista, isto é, sua transformação em mercadoria, não mais submetida à encomenda do mecenas ou da Igreja, a arte precisa ter atingido um grau de autonomia: só tendo como pressuposto a autonomia que a arte atinge sua condição de heteronomia.

A autonomia, sendo uma categoria pertencente ao todo do completo ideológico burguês, retém um momento de verdade (o deslocamento da arte da práxis vital) e um momento de não verdade (a hipóstase de um estado produzido historicamente como algo da essência da arte). Para Bürger:

A autonomia da arte é uma categoria da sociedade burguesa. Ela permite descrever a ocorrência histórica do desligamento da arte do contexto da práxis vital, descrever o fato de que, portanto, uma sensibilidade não comprometida com a racionalidade de fins pode se desenvolver junto aos membros das classes que, pelo menos temporariamente, estavam livres da pressão da luta cotidiana pela sobrevivência. Aí reside o momento de verdade do discurso da obra 
de arte autônoma. No entanto, o que essa categoria não consegue abarcar é que esse desligamento da arte do contexto da práxis vital representa um processo histórico, vale dizer, socialmente condicionado. E nisso, justamente, consiste a não verdade da categoria, o momento da deformação, que é próprio de toda ideologia - contanto que se use esse conceito no sentido da crítica da ideologia do Jovem Marx. A categoria da autonomia não permite compreender o seu objeto como tendo se tornado histórico. (2017, p. 109)

Agora, melhor delimitado o caráter idealista da autonomia da arte em relação às determinações sociais, podemos dizer que a questão da autonomia diz respeito ao momento subjetivo da produção artística, ou seja, a escolha do artista do que representar e como representar. Aqui, entra-se em uma série sem fim de contradições e pressupostos para tentar sustentar o argumento. Por um lado, o artista deve ter a autonomia para representar o que bem entender. No entanto, se escolher representar um conteúdo sócio-político, corre o risco de ser chamado de "tendencioso". Sua saída é representar esse conteúdo da forma mais distanciada e imparcial possível, ou seja, sem tomar partido, ou será acusado de "tendencioso". Mas o artista deve ser livre para representar o que bem entender! E assim, os defensores da autonomia subjetiva do artista impõem restrições às escolhas do artista, correndo atrás do próprio rabo.

Tal defesa da autonomia subjetiva do artista encontra seus próprios limites pois não supera uma visão mecanicista da relação entre indivíduo e sociedade. Esta visão não consegue perceber a determinação dialética entre o fator subjetivo do indivíduo (no nosso caso, do artista) e o fator objetivo do desenvolvimento social, ou seja, o fato histórico de que os sujeitos determinam o processo histórico da mesma forma como são determinados por ele. Percebem o desenvolvimento social (e ideológico) como apartado da atividade dos sujeitos singulares e, consequentemente, o sujeito isolado da totalidade histórico-social.

A percepção do sujeito como átomo foi já criticada enfaticamente por Marx e Engels (2003) e, portanto, não cabe aqui retomar os argumentos. É apenas de especial importância ressaltar que, assim como a autonomia da obra de arte necessariamente recai numa distorção idealista da produção social da arte, a autonomia subjetiva do artista demanda a mesma distorção idealista do processo criativo interior da obra de arte, pois parte do pressuposto (falso) de que a formação da subjetividade do artista não é fruto do desenvolvimento social objetivo. Neste sentido, nem a obra, nem o artista se encontram na torre de marfim, e podemos afirmar com segurança que toda arte é política. Isto, no entanto, não acrescenta muito ao debate, visto que é já terreno comum afirmar que mesmo a obra que se declara imparcial e isenta já está se posicionando politicamente.

A subjetividade do artista é um elemento de extrema importância para 
a compreensão da obra porque é a partir dela que compreendemos as escolhas feitas pelo artista do que representar e como representar. Mesmo que a obra em si não coincida com sua visão de mundo (Balzac, aqui, é o exemplo mais óbvio), há de se considerar a subjetividade do artista na análise da figuração artística do mundo próprio da obra. Isso porque, diferente de, por exemplo, a ciência, a produção artística requer o fator subjetivo para sua consumação, requer uma unidade entre objetividade e subjetividade4.

Até aqui, chegamos à conclusão que o rótulo de "tendência" muitas vezes é utilizado de forma arbitrária para definir aquele tipo de produção estética que mantém um caráter hostil à ordem estabelecida. Isso significa que não existe um elemento objetivo da "tendência" da obra de arte? De forma alguma. Dizemos que uma obra possui "tendência" quando sua figuração artística da realidade objetiva não se sustenta sobre a realidade mesma, mas sim sobre as opiniões e desejos do artista, seja ele progressista ou reacionário. Veja bem: não se trata de, no reflexo artístico, de negar a subjetividade do artista, seus desejos e opiniões, mas sim de compreender a diferença entre essa unidade entre objetividade e subjetividade na obra de arte, tal como defendido por Lukács, e a deformação da realidade na obra de arte como resultado de seu caráter tendencioso. Isto não significa, no entanto, que uma obra de arte que tome partido nas lutas de sua época é necessariamente "tendenciosa", ou que uma obra que almeje escapar do rótulo de tendência tenha que escapar para o reino da reportagem imparcial e "objetiva" (como o caso de Upton Sinclar na obra A selva).

Veja, aqui temos três situações distintas: na primeira, o artista deforma a realidade na sua figuração artística de acordo com suas opiniões e interesses, impondo uma primazia da sua subjetividade sobre a objetividade; na segunda situação, a representação “objetiva e imparcial”, típica da reportagem5, anula a própria representação ao impor uma primazia da objetividade da realidade sobre a subjetividade anulada do artista, retirando aquilo que há de especificamente estético na obra, ou seja, um privilégio unilateral do conteúdo sobre a forma (OLDRINI, 2019); e por último, temos uma representação que compreenda e se utilize da dialética entre o fator subjetivo e o fator objetivo na obra de arte, uma representação que tenha em unidade subjetividade do artista

4 Aqui, não dizemos que a ciência, por sua tendência à desantropomorfização (ou seja, à retirada do elemento humano como ideal) exclui um componente subjetivo do pesquisador, mas sim que sua atividade, se é realmente científica, segue a tendência da análise da realidade por ela mesma, independente das opiniões do artista.

5 A discussão sobre a Reportagem como substituto da representação, presente durante as primeiras décadas do século XX, é tema de debate de outro artigo de Lukács de 1932, Reportagem ou figuração? [Reportage oder Gestaltung?]. 
e objetividade do mundo representado ${ }^{6}$.

Aqui, nos encontramos em uma situação bastante complexa. Por um lado, temos os artistas “apartidários”, que seguem na ilusão de que podem distanciar-se dos conflitos ou da influência da realidade sobre sua própria consciência. Por outro lado, temos os escritores "tendenciosos", típicos, por exemplo, da Segunda Internacional, que ao escolher conscientemente uma tendência, deformam a realidade, porque aqui "não é uma tendência de desenvolvimento social em si, tornada apenas consciente pelo autor (no sentido de Marx), mas um mandamento (subjetivamente concebido) cuja realidade é exigida a atender" (LUKÁCS, 1971, p. 32). Entretanto, há um terceiro tipo de autor, aquele que supera justamente esse falso dilema entre “arte pura” e "arte de tendência”. É o caso, por exemplo, dos grandes realistas dos séculos XVIII e XIX, como Goethe, Balzac, Tolstói etc. (LUKÁCS, 2013) São estes que, apesar de suas visões de mundo particulares, conseguem apreender o movimento do real na sua figuração artística, como a condição do campesinato e dos servos na Rússia por Tolstói, ou a hipocrisia da aristocracia francesa por Balzac. Aqui, se confirma também a afirmação de Benjamin (2017) sobre uma tendência correta, ou seja, a tendência do movimento do real tal como sugerido por Marx, possui já em si todas as outras qualidades de uma obra de arte.

Esta figuração é aquilo que Lukács chama de partidariedade ou partidarismo [Parteilichkeit], ou seja, a "tomada de posição em face do mundo representado tal como ela toma forma na obra através de meios artísticos" (LUKÁCS, 1978, p. 209). Segundo o autor, é esta a superação do falso dilema entre "arte pura" e "arte de tendência" por ir além dos limites da falsa consciência típica da ideologia burguesa pela compreensão correta do desenvolvimento social. É neste sentido que Engels, em sua famosa carta a Minna Kautsky em 1885, defende a tendência - visto aqui como tendência do desenvolvimento social, não como a exigência ideal do autor que se justapõe à realidade:

Eu sou de opinião que a tendência deve surgir com naturalidade das
situações e da ação, sem que seja necessária a sua exposição especial;
e penso que o autor não está obrigado a apresentar ao leitor a futura
solução histórica dos conflitos sociais que descreve. Ademais, nas
nossas condições, o romance dirige-se preferencialmente ao leitor
do ambiente burguês, ou seja, que não pertence diretamente ao
nosso meio e, por esta razão, o romance de tendência socialista só

${ }^{6}$ Tal relação entre subjetividade e objetividade já está presente na primeira tese de Marx sobre Feuerbach: "O principal defeito de todo o materialismo existente até agora - o de Feuerbach incluído - é que o objeto [Gegenstand], a realidade, o sensível, só é apreendido sob a forma do objeto [Objekt] ou da contemplação; mas não como atividade humana sensível, como prática, não subjetivamente. Daí decorreu que o lado ativo, em oposição ao materialismo, foi desenvolvido pelo idealismo - mas apenas de modo abstrato, pois naturalmente o idealismo não conhece a atividade real, sensível, como tal." (MARX e ENGELS, 2007, p. 537) 
cumpre, a meu juízo, o seu objetivo quando reflete com veracidade as relações reais, rompe com as ilusões convencionais que existem sobre estas, fere o otimismo burguês e fomenta dúvidas acerca da imutabilidade das bases em que repousa a ordem existente - mesmo que o autor não proponha uma determinada solução ou que sequer se posicione ostensivamente (MARX e ENGELS, 2012, p. 66).

Aqui, está claro que Engels defende a tomada de partido por parte do artista. $\mathrm{O}$ autor deve encontrar a tendência no desenvolvimento social objetivo, ou seja, deve conhecer profundamente a realidade em si, os conflitos que permeiam suas relações, para que consiga romper com as ilusões convencionais que existem sobre as relações reais, no sentido de Engels. É, portanto, da especificidade da arte o seu caráter desmistificador, de romper com a falsa consciência burguesa e com o reflexo cotidiano da realidade, de revelar o movimento do real no seu aspecto mais humano; o partidarismo é, portanto, a revelação do reflexo artístico como embate entre reação e progresso e somente o proletariado - de acordo com Lukács - é capaz de romper com a falsa consciência mistificada da decadência ideológica burguesa.

Em vias de uma conclusão, cabe ainda responder a dois possíveis erros decorrentes da análise realizada acima. $O$ primeiro diz respeito ao papel da subjetividade do autor na produção artística. $\mathrm{O}$ segundo, em relação à defesa da autonomia. Nenhum dos problemas pode ser abordado aqui em sua totalidade, sendo necessário apenas mostrar os possíveis caminhos do seguimento do debate.

A defesa do partidarismo na arte feita por Lukács, do artista conseguir descobrir no real as tendências objetivas do movimento histórico, pode desembocar numa falsa conclusão de que o artista deve realizar uma análise científica da realidade. Portanto, ele deve se voltar para uma análise fidedigna e fotográfica da realidade. Nada poderia ser mais oposto à visão lukacsiana de reflexo artístico. Já de início, essa concepção se mostra falsa devido à concepção do ato do trabalho que, segundo Lukács, por permitir a superação da subjetividade espontânea, por suspender a imediatez da atividade (pelo seu aspecto teleológico), permite ao sujeito não só investigar a realidade objetiva tal como ela é em si, mas justamente por isso, permite a distinção entre o essencial e o não-essencial na realidade objetiva, refletida na consciência humana (LUKÁCS, 1966).

De que forma isso se manifesta no reflexo estético? O mesmo processo de distinção entre o essencial e o não-essencial se manifesta na atividade estética do sujeito. É da possibilidade de superar a consciência imediata que o ser humano consegue ir além da aparência fenomenológica da coisa em direção à sua essência, o détour do processo de conhecimento, tal como categorizado por Kosik (1976), ainda que esse détour realizado pelo reflexo artístico seja 
diferente do reflexo científico. A defesa do realismo da obra de arte significa a capacidade da obra de ir além da simples aparência do fenômeno, capacidade intimamente relacionado com a subjetividade criadora do artista de conscientemente analisar a realidade objetiva.

Tal concepção, ainda que não elaborada com a complexidade presente na grande Estética, já está presente nos primeiros textos de Lukács após sua "virada marxista". Esta pode ser encontrada não somente em Tendência ou partidarismo (1932), mas também em Reportagem ou figuração? (1932) e Narrar ou descrever? (1937)7. No primeiro texto, o autor critica o método jornalístico que objetiva a reprodução direta e fiel da realidade empírica, com a intenção de demonstrar que o caso retratado é típico e representativo de uma parcela maior da realidade, deixando de lado o aspecto subjetivo das personagens. Essa lacuna é preenchida, segundo Lukács, pela subjetividade não-retratado do autor, como um comentário moralizante que é supérfluo e acidental", sendo prejudicial à própria trama narrativa. Já na segunda produção (Narrar ou descrever?), o autor critica a mera observação do narrador, que se contenta em descrever de maneira fotográfica a realidade retratada. Torna-se uma realidade morta, cristalizada e fetichizada, indo contra a função social do reflexo estético, a "dissolução do fetichismo das relações sociais e econômicas sob o capitalismo" (COTRIM, 2016, p. 163).

É neste sentido que Lukács critica a reportagem e o naturalismo como métodos de representação artística do real. O partidarismo defendido pelo autor, portanto, não se baseia em uma mera reprodução fotográfica do real, mas sim na capacidade do artista de configurar a "tendência" objetiva, possível apenas devido ao ato consciente de selecionar entre o essencial e o nãoessencial. É neste sentido também que Steiner postula: "enquanto o realista seleciona, o naturalista enumera” (STEINER, 1988, p. 293).

A outra questão mencionada diz respeito à autonomia da arte. Defender o partidarismo/partidariedade da obra pode ser erroneamente interpretado como uma crítica à autonomia da produção artística, que a obra deva estar a serviço de um partido e, portanto, deve ser direcionada ou regida por fatores externos à própria atividade criativa, como diretrizes ou normas. De forma alguma. Para além da compreensão não-dialética da relação entre sujeito e sociedade, como já explicitado anteriormente, esta concepção compreende autonomia apenas como autonomia absoluta, hipostasiada. No polo oposto, temos, por exemplo, os movimentos vanguardistas e neovanguardistas que buscam rebaixar a obra de arte ao nível da cotidianidade, como um happening.

Ambos os extremos - a concepção idealista e descolada da realidade de

7 Uma análise mais completa acerca destes textos pode ser vista na obra Literatura e realismo em György Lukács, de Ana Cotrim, baseada em sua dissertação de mestrado. 
autonomia e o rebaixamento da obra ao nível da cotidianidade - são repudiáveis na medida em que ignoram a peculiaridade específica da obra de arte e ou a descolam do contexto histórico de sua produção, ou o reduzem a uma determinação vulgar e mecânica. Aqui, deve-se entender a autonomia da obra de arte da mesma forma como os outros complexos sociais: que, em determinadas condições históricas, ganham uma autonomia relativa em relação à totalidade social, nunca descolando-se totalmente desta totalidade. Da mesma forma, defender esta autonomia, para Lukács, representa a possibilidade da função da obra de arte de desvelar o fetiche da realidade cotidiana imediata (ou como Kosík coloca, o mundo da pseudoconcreticidade), contrariando a tendência aos movimentos vanguardistas de identificarem a obra com essa mesma cotidianidade.

Aqui, torna-se evidente que defender a autonomia da arte não se coloca em oposição à defesa do partidarismo da obra; pelo contrário, ambas são essenciais para o sucesso ou não da obra de arte em sua missão desfetichizadora. Superado o falso debate entre uma arte política e uma arte livre, "autônoma", abre-se o caminho para compreender o papel da autonomia de uma perspectiva materialista e dialética. Somente indo além do falso dilema entre autonomia ou politização da arte podemos compreender a subsunção da arte dentro do modo de produção capitalista e suas possibilidades reais de emancipação.

\section{Referências bibliográficas}

BENJAMIN, W. Estética e sociologia da arte. Belo Horizonte: Autêntica, 2017. BÜRGER, P. Teoria da vanguarda. São Paulo: Ubu Editora, 2017.

COTRIM, A. Literatura e realismo em György Lukács. Porto Alegre: Zouk, 2016.

FREDERICO, C. Movimentos artísticos e política cultural. Estudos Avançados, v. 92, pp. 105-18, 2018.

HEGEL, G. W. F. Enciclopédia das ciências filosóficas em compêndio v. 1: A ciência da lógica. São Paulo: Loyola, 1995.

KOSIK, K. Dialética do concreto. São Paulo: Paz e Terra, 1976.

LIFSCHITZ, M. K. Voprosu o Vzglyadakh Marksa na Iskusstvo. Moscou: [s.n.], 1933.

LUKÁCS, G. La peculiaridad de lo estetico v. 2: Problemas de la mímesis. Trad. Manuel Sacristán. Barcelona: Grijalbo, 1966.

LUKÁCS, G. Tendenz oder Parteilichkeit. In: . Werke 4 v. Probleme des Realismus I: Essays über Realismus. Berlim: Luchterhand, 1971, p. 23-34. LUKÁCS, G. Introdução a uma estética marxista. Rio de Janeiro: Civilização Brasileira, 1978. 
Popular, 2010.

Marxismo e teoria da literatura. 2. ed. São Paulo: Expressão Poetry of the Party. In:

The culture of people's democracy: Hungarian essays on literature, art, and democratic transition. Leiden: Brill, 2013, p. 105-28.

MARX, K.; ENGELS, F. A sagrada família. São Paulo: Boitempo, 2003. . A ideologia alemã. São Paulo: Boitempo, 2007.

. Cultura, arte e literatura: textos escolhidos. São Paulo: Expressão

Popular, 2012.

NAPOLITANO, M. Arte e revolução: entre o artesanato dos sonhos e a engenharia das almas (1917-1968). Revista de Sociologia e Política, Curitiba, pp. 7-20, 1997.

OLDRINI, G. Os marxistas e as artes: princípios de metodologia crítica marxista. Maceió: Coletivo Veredas, 2019.

STEINER, G. Linguagem e silêncio: ensaios sobre a crise da palavra. São Paulo: Companhia das Letras, 1988.

Como citar:

BIANCHI, Bruno Daniel. Arte autônoma ou arte política? Verinotio - Revista on-line de Filosofia e Ciências Humanas, Rio das Ostras, v. 26, n. 1, pp. 85-95, jan./jun. 2020.

Data do envio: 15 mar. 2020

Data do aceite: 18 maio 2020 